\title{
Apolipoproteins J and E co-localise with amyloid in gelatinous drop-like and lattice type I corneal dystrophies
}

Kohji Nishida, Andrew J Quantock, Atsuyoshi Dota, Nam-Ho Choi-Miura, Shigeru Kinoshita

\begin{abstract}
Aims-Apolipoprotein J (apoJ) and apolipoprotein $E$ (apoE) are thought to contribute to amyloid formation in patients with Alzheimer's disease. The aim of this investigation was to discover whether or not these apolipoproteins associate with corneal amyloid in gelatinous drop-like corneal dystrophy (GDCD) and lattice corneal dystrophy type I (LCD-I).

Methods-Corneas from three eyes of three patients with GDCD and one eye of one patient with LCD-I were examined immunohistochemically using antibodies against apoJ and apoE. Two normal corneas were similarly examined. Tissue sections of brain from a patient with Alzheimer's disease were used as positive controls for the antibodies. For all negative controls, mouse IgG was used instead of the primary antibody.

Results-Intense apoJ and apoE immunoreactivities were found in congophilic amyloid deposits in GDCD and LCD-I. These deposits were located subepithelially in GDCD, and subepithelially and intrastromally in LCD-I. In GDCD, immunostaining of subepithelial amyloid with anti-apoJ was noticeably stronger than with anti-apoE.

Conclusions-As in senile plaques in brain from a patient with Alzheimer's disease, apoJ and apoE co-localise with amyloid in corneas with GDCD and LCD-I.

(Br f Ophthalmol 1999;83:1178-1182)
\end{abstract}

Ophthalmology, Kyoto Prefectural University of Medicine, Kyoto, Japan

K Nishida

A J Quantock ${ }^{\star}$

A Dota

S Kinoshita

Department of Physiological

Chemistry, Showa

University, Tokyo,

Japan

N-H Choi-Miura

${ }^{\star}$ Current address: Department of Optometry and Vision Sciences, Cardiff University, Cardiff.

Correspondence to Shigeru Kinoshita, MD, PhD, Department of Ophthalmology, Kyoto Prefectural University of Medicine, Kawaramachi Hirokoji, Kamigyo-ku, Kyoto 602, Japan.

Accepted for publication 25 June 1999
The deposition of amyloid in the cornea is a feature of several corneal pathologies. Gelatinous drop-like corneal dystrophy (GDCD) is one such example-a condition in which an extensive accumulation of amyloid beneath the epithelium severely limits vision and gives the surface of the affected cornea a mounded, mulberry-like appearance. ${ }^{1}$ This predominantly Asian disease was first recognised in $1914,{ }^{2}$ and today is also known, probably more informatively, as familial subepithelial corneal amyloidosis. Amyloid is also deposited in corneas with lattice corneal dystrophy type I (LCD-I), although here its distribution tends to be more widespread with respect to stromal depth than in GDCD because it can be located intrastromally as well as subepithelially. ${ }^{3}$ In LCD-I the pattern of amyloid deposition gives the cornea its distinctive appearance with fine lattice lines easily evident on clinical examination.

Genetically, GDCD and LCD-I are distinct. The gene for LCD-I has been mapped to chromosome $5 \mathrm{q} 31,{ }^{45}$ and most published reports show that it is caused by an Arg124Cys mutation in $\mathrm{BIG}-\mathrm{H} 3,{ }^{6-8}$ the gene that codes for the protein keratoepithelin. In contrast, $\beta I G-H 3$ is not mutated in GDCD. ${ }^{9}$ Rather, the responsible gene has been mapped to chromosome $1 \mathrm{p}^{10}$ where, very recently, four mutations of the cell surface glycoprotein M1S1 (previously known as GA733-1 or TROP2) were found. ${ }^{11}$

Numerous investigations have indicated that the formation of amyloid plaques in the brains of patients with Alzheimer's disease is related to the presence in this tissue of a number of apolipoproteins, among them apolipoprotein $\mathrm{J}$ (apoJ) and apolipoprotein E (apoE). ${ }^{12-20}$ For example, immunochemical studies have identified apoJ as a constituent of amyloid in Alzheimer's disease, ${ }^{14}$ while in vitro biochemical work has shown that this apolipoprotein binds to amyloid precursor protein, thereby promoting amyloid formation. ${ }^{15-17}$ Other studies have similarly linked apoE with amyloid deposition in Alzheimer's disease. ${ }^{18-20}$ In view of the evidence suggesting that apoJ and apoE contribute to amyloid formation in Alzheimer's disease, we sought to examine their distribution in relation to accumulated amyloid in GDCD and LCD-I.

\section{Patients and methods}

With informed consent, we examined corneas from three eyes of three patients with a clinical diagnosis of GDCD (47 year old man, 50 year old woman, and 72 year old woman) and one eye of one patient diagnosed with LCD-I (71 year old woman). LCD-I tissue was obtained immediately after a penetrating keratoplasty, GDCD tissue after a lamellar keratoplasty. In order to confirm the clinical diagnoses on a molecular level genomic DNA was isolated from patients' blood and used as a template for the polymerase chain reaction (PCR) to amplify all 17 exons of the coding region of $\beta I G-H 3$. The PCR product was then sequenced. After surgery, excised corneas were snap frozen, sectioned ( $7 \mu \mathrm{m}$ thick sections), fixed in $70 \%$ ethanol $\left(4^{\circ} \mathrm{C}\right.$ for 10 minutes), and stained for amyloid with congo red. Photomicrographs were then taken under polarised light. Immunolocalisation of apoJ and apoE was performed in accordance with our 
previous report. ${ }^{21}$ In brief, $7 \mu \mathrm{m}$ thick, fixed sections were incubated at room temperature in $1 \%$ hydrogen peroxide for 1 hour, followed by $3 \%$ bovine albumin for 1 hour. They were then incubated $\left(12\right.$ hours at $\left.4^{\circ} \mathrm{C}\right)$ with the primary antibody. For apoJ we used two monoclonal antibodies-G7 (a kind gift from Dr Brendan Murphy, St Vincent's Hospital, Melbourne, Australia ${ }^{22}$ ) and IVF4 (produced by one of the authors (Choi-Miura) ${ }^{23}$ ), both of which had been raised against apoJ. These were diluted to yield IgG concentrations of 5 $\mu \mathrm{g} / \mathrm{ml}$ and $2.5 \mu \mathrm{g} / \mathrm{ml}$, respectively. The primary antibody against apoE was purchased from Innogenetics, SA (Zwijundrecht, Belgium) and was diluted to yield an IgG concentration of 5 $\mu \mathrm{g} / \mathrm{ml}$. Two normal corneas obtained at necropsy (75 year old woman and 68 year old man) and treated identically to the dystrophic corneas were used as non-amyloidotic controls. As a positive control for the antibodies, brain tissue from the necropsied frontal lobe of a 93 year old woman who had died of Alzheimer's disease was studied. In all cases,
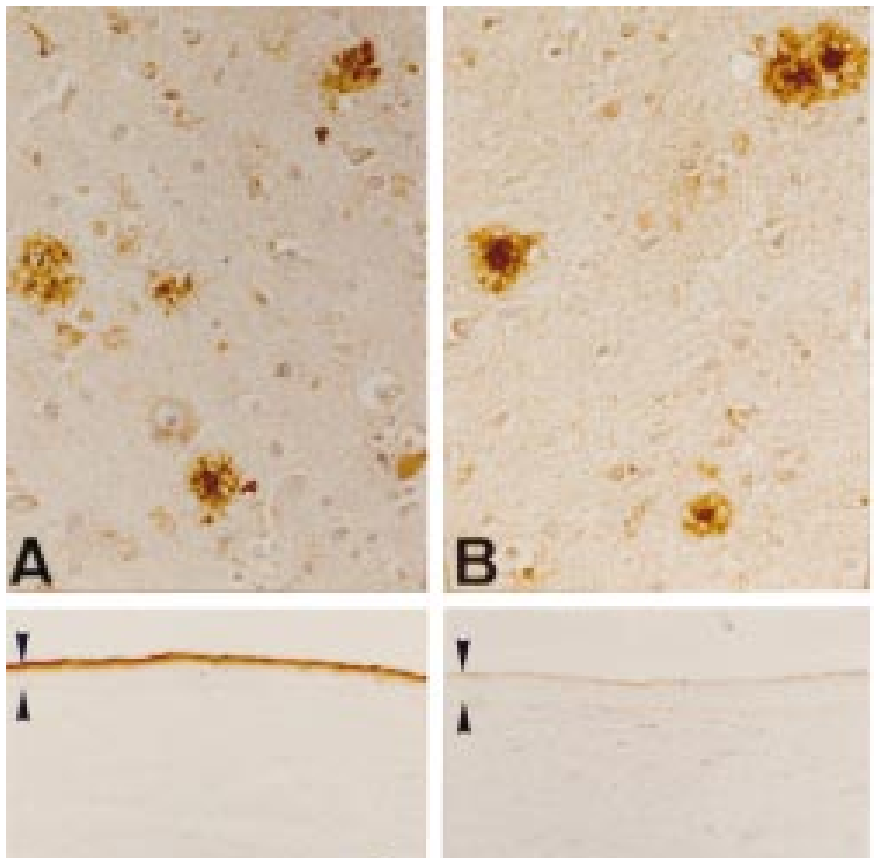

S

D
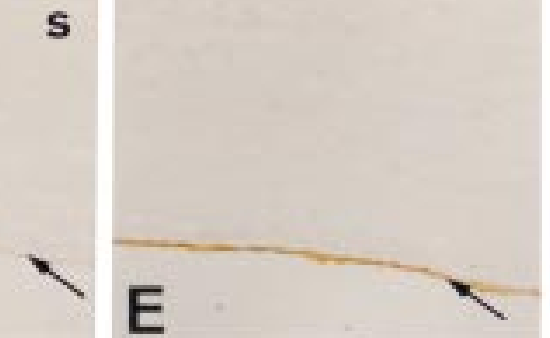

Figure 1 (A-C) Immunostaining of brain from a patient who had died of Alzheimer's disease with antibodies to (A) anti-apolipoprotein $\mathcal{f}$ and $(B)$ anti-apolipoprotein E. Positive immunostaining is seen in senile plaques. (C) Control section incubated with normal mouse serum IgG shows no discernible immunolabelling. (D-F) Immunostaining of normal cornea with anti-apolipoprotein $\mathcal{F}$ and anti-apolipoprotein $E$ antibodies. The epithelium is delineated by arrowheads, and the endothelium identified by an arrow; $s=$ stroma. (D) The antibodies to apolipoprotein $\mathcal{F}$ stain the superficial epithelium (as was found previously ${ }^{21}$ ), whereas (E) the antibody to apolipoprotein $E$ antibody does not stain epithelium. (E) Anti-apolipoprotein $E$ appears to stain the endothelial/Descemet's membrane region, although at this time we cannot totally rule out the possibility that this might represent an edge artefact. (D, E) Diffuse staining for apolipoprotein $\mathcal{F}$ and apolipoprotein $E$ was found in stroma. (F) Control section incubated with normal mouse serum IgG shows no discernible immunolabelling. Bar=50 $\mu \mathrm{m}(A-C)$ and $100 \mu \mathrm{m}(D-F)$. negative control sections were incubated with normal mouse IgG instead of the primary anti-

\section{Results}

In the patient diagnosed with LCD-I we detected an Arg124Cys mutation in exon 4 of 3ene (on chromosome 5q31). Several previous studies have found this mutation CD-I. ${ }^{6-8}$ The coding region of the $\beta$ IG-H3 patients examined here, consistent with our previous study of individuals with this disease, ${ }^{9}$ as well as with the very recent assignment of some $1 \mathrm{p} .^{1011}$

Positive immunostaining for apoJ (Fig 1A) and apoE (Fig 1B) was found in senile plaques of brain tissue from a patient who had died of ' When the primary antiwere replaced by mouse IgG, no ing evident (Fig 1C). In normal tense in the outer epithelial layers (Fig 1D), similar to our previous report. ${ }^{21}$ Anti-apoE, on
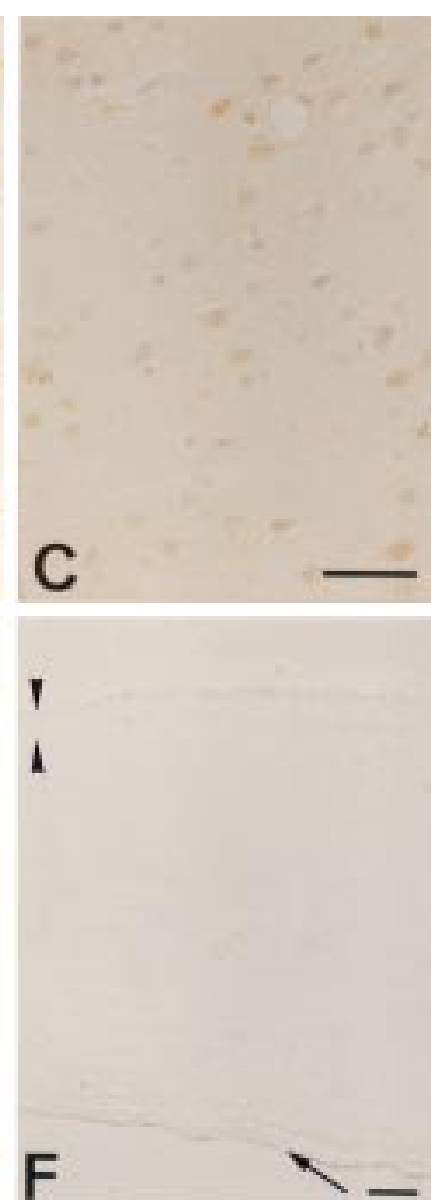

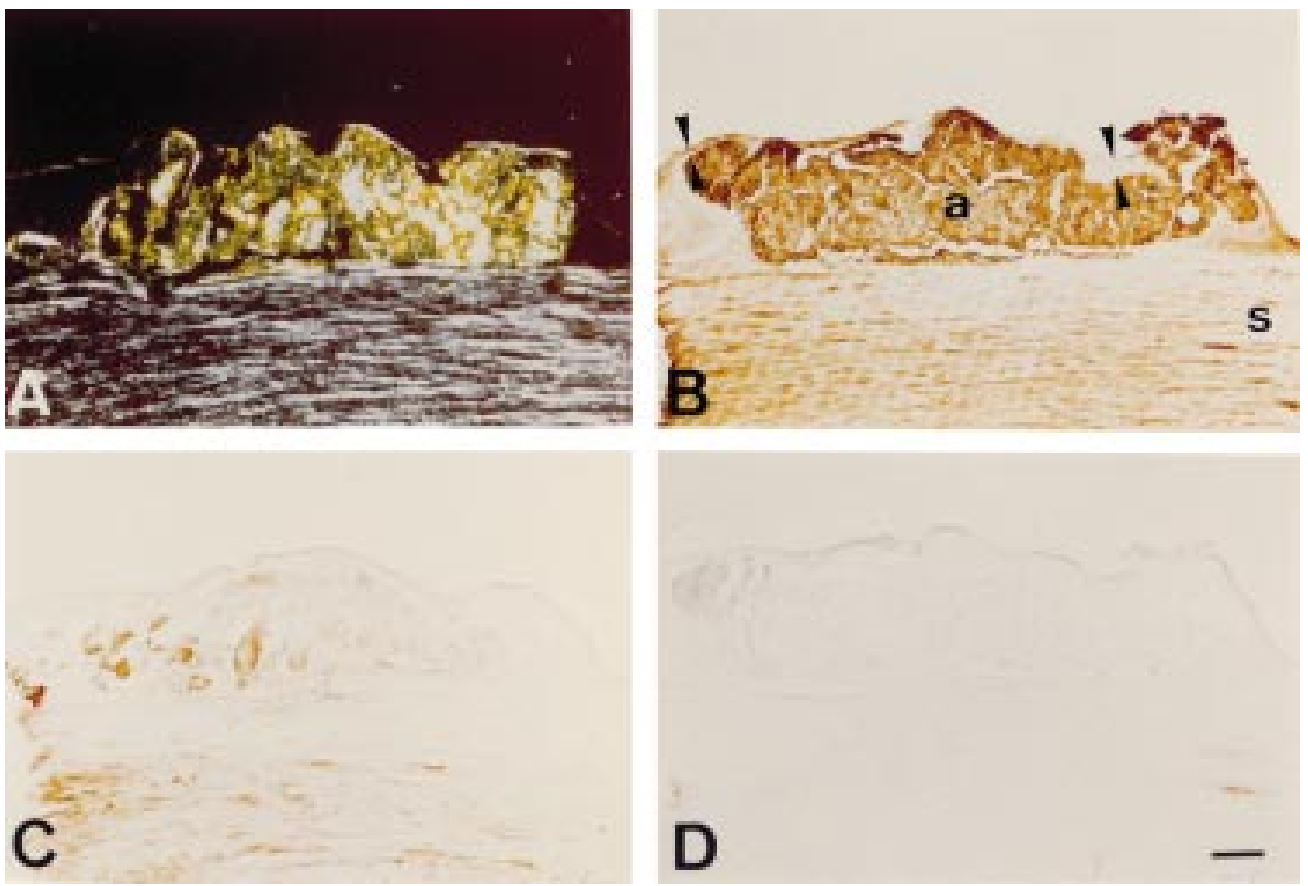

Figure 2 Immunostaining of gelatinous drop-like corneal dystrophy cornea with anti-apolipoprotein $\mathcal{f}$ and anti-apolipoprotein $E$ antibodies. The epithelium (delineated by arrowheads in $(B)$ ) varies greatly in thickness. $(A)$ When viewed under polarised light, congo red staining is seen in epithelial and subepithelial regions, showing a birefringent polarisation typical of amyloid. The posterior cornea is not visible here because tissue was obtained by a lamellar keratoplasty. (B) The antibodies to apolipoprotein 7 stain the subepithelial amyloid deposit (a) fairly intensely, and the stroma (s) more diffusely. (C) The anti-apolipoprotein E antibody also stains amyloid, but much less strongly than the anti-apolipoprotein $\mathcal{F}$ antibodies. (D) Control section incubated with normal mouse serum IgG shows no discernible immunolabelling. Bar $=100 \mu \mathrm{m}$

the other hand, did not stain epithelium (Fig $1 \mathrm{E})$. We do appear to find immunostaining for apoE in the region of Descemet's membrane and/or the endothelium (Fig 1E); however, we hesitate to draw any strong conclusions from
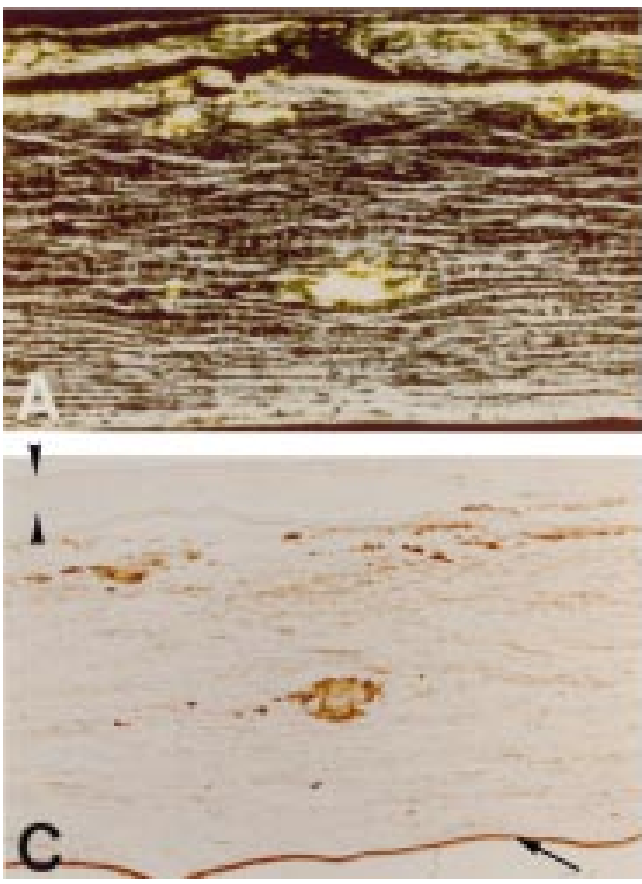

this at this stage because the possibility that it represents an edge artefact has not yet been excluded. No specific staining for either apoJ or apoE was found in normal stroma (Figs 1D and E). Negative control sections of normal
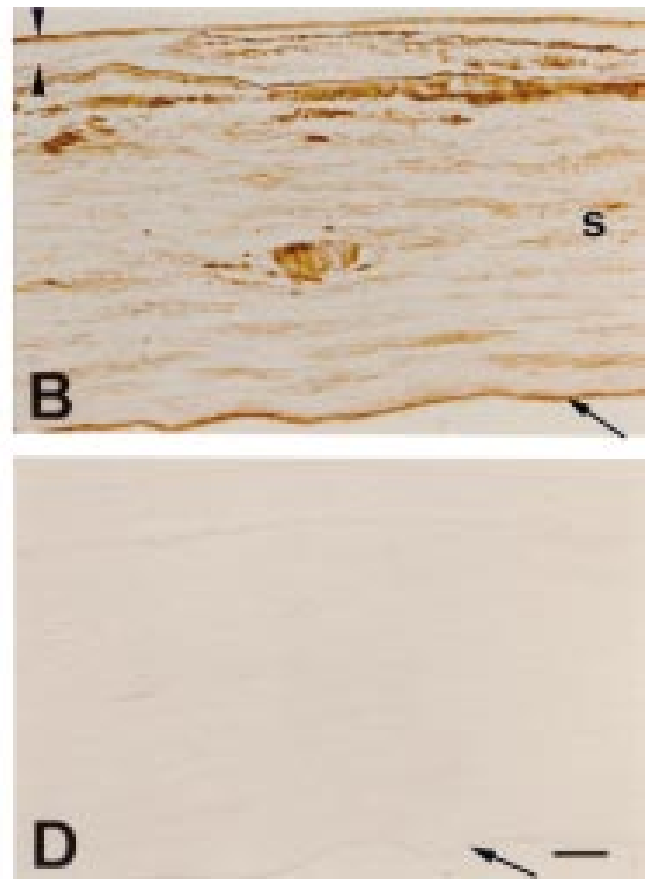

Figure 3 Immunostaining of a lattice corneal dystrophy type I cornea with anti-apolipoprotein 7 and anti-apolipoprotein $E$ antibodies. The epithelium is delineated by arrowheads, and the endothelium identified by an arrow. (A) When viewed under polarised light, congo red staining is seen subepithelially and in corneal stroma, showing birefringent polarisation typical of amyloid. (B) Immunostaining for apolipoprotein $\mathcal{f}$ clearly mirrors the distribution of subepithelial and

intrastromal amyloid deposits. (C) Apolipoprotein E immunoreactivity also co-exists with amyloid, but appears to stain the section less strongly than the apolipoprotein f antibodies. (D) Control section incubated with normal mouse serum IgG shows no discernible immunolabelling. Bar $=100 \mu \mathrm{m}$. 
cornea incubated with normal mouse serum IgG instead of a primary antibody showed no discernible labelling over the entire section (Fig 1F).

Unlike the normal corneas examined here, all three GDCD corneas displayed birefringent congo red positive areas when viewed under polarised light (Fig 2A). This is a characteristic of amyloid, and in GDCD we found that most congophilic material was located subepithelially (Fig 2A). We also found that apoJ and apoE immunoreactivities in the GDCD stroma (Figs 2B and C) were above levels detected in normal cornea (Fig 1D and E) and that this stromal immunoreactivity appeared to be stronger in the case of apoJ. The apoE antibody did not stain corneal epithelium in GDCD whereas the apoJ antibody did, albeit less strongly than in controls (Figs $2 \mathrm{~B}$ and $\mathrm{C}$ ). However, by far the most striking feature of the apoJ and apoE immunohistochemistry in GDCD was the intense staining of the extensive subepithelial amyloid with the antibodies to apoJ (Fig 2B). This subepithelial amyloid was also immunoreactive with the antibody to apoE but to a lesser extent (Fig 2C). Negative control sections incubated with normal mouse serum IgG in place of the primary antibody showed no discernible specific labelling over the entire tissue section (Fig 2D).

Again, unlike normal cornea the LCD-I cornea displayed birefringent congo red positive areas when viewed under polarised light (Fig $3 \mathrm{~A})$. In this disease the congophilic amyloid was mostly located subepithelially, with some also found deeper in the stroma. Like GDCD, the LCD-I cornea immunoreacted with the apoJ and apoE antibodies (Figs $3 \mathrm{~B}$ and $\mathrm{C}$ ). Diffuse immunostaining for apoJ and apoE (above the levels found in normal cornea) was detected in the stroma. As in normal cornea, the corneal epithelium in LCD-I was immunoreactive with the antibodies to apoJ but not with the antibody to apoE. Also, as was the case for GDCD, the most intense staining with the anti-apoJ and anti-apoE antibodies in the LCD-I cornea was noted in the congophilic amyloid deposits (Figs 3B and C). Negative control sections incubated with normal mouse serum IgG instead of the primary antibody showed no discernible labelling (Fig 3D).

\section{Discussion}

As mentioned earlier, apolipoproteins, including apoJ and apoE, are thought to be important in the pathogenesis of Alzheimer's disease..$^{12-20}$ A major constituent of the fibrils comprising senile plaques and cerebrovascular amyloid deposits in Alzheimer's disease is amyloid beta (A $\beta) .{ }^{24}{ }^{25}$ This peptide is also known to be an internal degradation product of a larger precursor, amyloid precursor protein, that binds to cell membranes. ${ }^{26}$ In addition, $A \beta$ is a soluble normal constituent (sA $\beta$ ) of biological fluids and cell culture supernatants, ${ }^{27}{ }^{28}$ and while it is unclear whether $\mathrm{sA} \beta$ is the immediate precursor of $A \beta$, some in vitro studies have indicated that apoJ and apoE bind to synthetic A $\beta$ with high avidity and promote amyloid for- mation from $A \beta .^{15-20}$ This body of evidence strongly suggests that apoJ and apoE contribute to the formation of amyloid in Alzheimer's disease by acting as $\mathrm{A} \beta$ carrier proteins (so called pathological chaperones). The results of the present study for the first time indicate that apoJ and apoE co-localise with amyloid deposits in GDCD and LCD-I corneas, just as they do in senile plaques in Alzheimer's brain tissue. This leads us to consider the possibility that, as is thought to occur in Alzheimer's disease, apoJ and apoE might be acting as pathological chaperones for amyloid formation in GDCD and LCD-I corneas. We are not aware of any studies regarding apoE in human cornea, but apoJ certainly appears to be an important corneal constituent. In the mature human eye, for example, we have found mRNA for apoJ in the corneal endothelium, ${ }^{29}$ as well as in the epithelium, ${ }^{21}$ where it is the most abundant gene transcript. ${ }^{30}$ In addition, immunohistochemistry has located apoJ (also known as clusterin or SP-40,40) in corneal epithelial ${ }^{21}$ and endothelial cells, ${ }^{29}$ and biochemical assays have also found it in vitreous ${ }^{31}$ and aqueous. ${ }^{29} 31$ From a functional viewpoint, it is known that suppression of apoE can drastically reduce amyloid deposition in murine brain tissue, ${ }^{32}$ and this then offers a potential route for treating diseases such as Alzheimer's. If we find that apoJ and/or apoE deposition does indeed promote amyloid formation in certain corneal amyloidoses they offer themselves as candidates for new treatment regimens.

It is noteworthy that the immunoreactivity of apoJ and apoE in the corneal amyloid deposits in GDCD and LCD-I was rarely homogeneous, something that might well be reflective of the presence of other constituents in the deposits. A likely candidate in LCD-I is the degraded form of keratoepithelin, a protein that has been found in subepithelial deposits in this disease, ${ }^{33}$ and one that also accumulates and co-localises with congophilic amyloid deposits in another corneal amyloidosis, LCD III-A. ${ }^{34}$ In GDCD a material that might co-localise with amyloid, apoJ, and apoE is lactoferrin, a protein that was recently discovered in amyloid deposits in this disease. ${ }^{35} \mathrm{In}$ view of the fact that the lactoferrin gene is not mutated in GDCD, ${ }^{36}$ and because the corneal epithelial barrier function is severely compromised in this condition ${ }^{37}{ }^{38}$ we suspect that the origin of the lactoferrin in GDCD deposits might well be the tears.

It is clear from the results of this study that apoJ and apoE co-localise with corneal amyloid in GDCD and LCD-I. It is conceivable that either or both of these apolipoproteins might promote the formation of amyloid in GDCD and LCD-I corneas, just as they are thought to in Alzheimer's disease. Alternatively, it is of course also possible that apoJ and apoE might be accumulating secondarily to amyloid in these diseases along with other proteins such as lactoferrin (in $\mathrm{GDCD}^{35}$ ) and degraded keratoepithelin (in LCD-I ${ }^{33}$ ). Further studies are required to investigate the possible deposition of apoJ and apoE in other corneal amyloidoses, and to better understand 
the involvement of these apolipoproteins in the pathogenesis of GDCD and LCD-I.

The authors thank Drs Makio Kobayashi and Yasuo Ihara for The authors thank Drs Makio Kobayashi and Yasuo Thara for their assistance in the preparation of this manuscript and Dr Murphy for the kind gift of his G7 anti-apolipoprotein antibody. This study was supported in part by research grants 08457467 and 08771509 from the Japanese Ministry of Education, Culture and Science and a research fund from
Foundation for the Promotion of Medical Science.

1 Li S, Edward DP, Ratnaker KS, et al. Clinicohistopathological findings of gelatinous drop-like corneal dystrophy among Asians. Cornea 1996;15:355-62.

2 Nakaizumi G. A rare case of corneal dystrophy. Nippon Ganka Gakkai Zasshi 1914;18:949-50.

3 Kivelä T, Tarkkanen, McLean I, et al. Immunohistochemical analysis of lattice corneal dystrophies types I and II. $\mathrm{Br} \mathcal{F}$ Ophthalmol 1993;77:799-804.

4 Stone EM, Mathers WD, Rosenwasser GOD, et al. Three autosomal dominant corneal dystrophies map to chromosome 5q. Nat Genet 1994;6:47-52.

5 Gregory CY, Evans K, Bhattacharya S. Genetic refinement of the chromosome 5 lattice corneal dystrophy type I locus to within a 2cM interval. $\mathcal{F}$ Med Genet 1995;32:224-6.

6 Munier FL, Korvatska E, Djemai A, et al. Kerato-epithelin mutations in four 5q31-linked corneal dystrophies. Nat Genet 1997;15:247-51.

7 Korvatska E, Munier FL, Djemai A, et al. Mutation hot spots in 5q31-linked corneal dystrophies. Am $\mathcal{F}$ Hum Genet 1998;62:320-4.

8 Gupta S, Hodge WG, Damji KF, et al. Lattice corneal dystrophy type I in a Canadian kindred is associated with the Arg $124 \rightarrow$ Cys mutation in the kerato-epithelin gene. Am $\mathcal{F}$ Ophthalmol 1998;125:547-9.

9 Dota A, Nishida K, Honma Y, et al. Gelatinous drop-like corneal dystrophy is not one of the $\beta$ ig-h3-mutated corneal amyloidoses. Am f Ophthalmol 1998;126:832-3.

10 Tsujikawa M, Kurahashi $\mathrm{H}$, Tanaka T, et al. Homozygosity mapping of a gene responsible for gelatinous drop-like corneal dystrophy to chromosome 1p. Am f Hum Genet 1998; 63:1073-7.

11 Tsujikawa $M$, Kurahashi $H$, Tanaka $T$, et al. Identification of the gene responsible for gelatinous drop-like corneal dystrophy. Nat Genet 1999;21:420-3.

12 Wisniewski T, Golabek AA, Kida E, et al. Conformational mimicry in Alzheimer's disease. Role of apolipoproteins in mimicry in Alzheimer's disease. Role of apolipopro

13 Harr SD, Uint L, Holloster R, et al. Brain expression of apolipoproteins E, J and A-I in Alzheimer's disease. $7 \mathrm{Neu}$ rochem 1996;66:2429-35.

14 Choi-Miura N-H, Ihara Y, Fukuchi K, et al. SP-40,40 is a constituent of Alzheimer's amyloid. Acta Neuropathol 1992; $83: 260-4$.

15 Matsubara E, Frangione B, Ghiso J. Characterization of apolipoprotein J-Alzheimer's interaction. I Biol Chem 1995;31:7563-7.

16 Ghiso J, Matsubara E, Koudinov A, et al. The cerebrospinalfluid soluble form of Alzheimer's amyloid beta is complexed to SP-40,40 (apolipoprotein J), an inhibitor of the complement membrane-attack complex. Biochem f 1993 293: $27-30$

17 Oda T, Wals $\mathrm{P}$, Osterburg $\mathrm{HH}$, et al. Clusterin (apoJ) alters the aggregation of amyloid b-peptide (A beta I-42) and forms slowly sedimenting A beta complexes that cause oxiforms slowly sedimenting A beta complexes

18 Strittmatter WJ, Saunders AM, Schmechel D, et al. Apolipoprotein E: high-avidity binding to b-amyloid and increased frequency of type 4 allele in late-onset familial Alzheimer disease. Proc Natl Acad Sci USA 1993;90:197781.
19 Strittmatter WJ, Weisgraber KH, Huang DY, et al. Binding of human apolipoprotein $\mathrm{E}$ to synthetic amyloid $\mathrm{b}$ peptide: isoform-specific effects and implications for late-onset Alzheimer disease. Proc Natl Acad Sci. USA 1993;90:8098102.

20 Wisniewski TEM, Castano A, Gloabek T, et al. Acceleration of Alzheimer's fibril formation by apolipoprotein $\mathrm{E}$ in vitro. Am f Pathol 1994;145:1030-5.

21 Nishida K, Kawasaki S, Adachi W, et al. Apolipoprotein J expression in human ocular surface epithelium. Invest Ophthalmol Vis Sci 1996;37:2285-92.

22 Murphy BF, Kirszbaum L, Waker ID, et al. SP-40,40, a newly identified normal human protein found in the SC5b-9 complex of complement and in the immune deposits in glomerulonephritis. $\mathcal{F}$ Clin Invest 1988;81:185864 .

23 Choi N-H, Tobe T, Hara K, et al. Sandwich ELISA assay for quantitative measurement of SP-40.40 in seminal plasma and serum. F Immunol Meth 1990;131:159-63.

24 Glenner GG, Wong CW. Alzheimer's disease: initial report of the purification and characterization of a novel cerebrovascular amyloid protein. Biochem Biophys Res Commun 1984;120:885-90.

25 Masters CL, Simms G, Weinman NA, et al. Amyloid plaque core protein in Alzheimer disease and Down syndrome. Proc Natl Acad Sci USA 1985;82:4245-9.

26 Kang J. Lemaire H-G, Multhaup G, et al. The precursor of Alzheimer's disease amyloid A4 protein resembles a cell-surface receptor. Nature 1987;325:733-6.

27 Shoji M, Golde TE, Ghiso J, et al. Production of the Alzheimer amyloid b-peptide protein by normal proteolytic processing. Science 1992;58:126-9.

28 Hassen C, Schlossmacher MG, Hung AY, et al. Amyloid b-peptide is produced by cultured cells during normal metabolism. Nature 1992;359:322-5.

29 Dota A, Nishida K, Quantock AJ, et al. Clusterin in human corneal endothelium and aqueous humor. Exp Eye Res 1999; (in press).

30 Nishida K, Adachi W, Shimizu-Matsumoto A, et al. A gene expression profile of human corneal epithelium and the isolation of human keratin $12 \mathrm{cDNA}$. Invest Ophthalmol Vis Sci 1996;37:1800-9.

31 Reeder DJ, Stuart WD, Witte DP, et al. Local synthesis of apolipoprotein J in the eye. Exp Eye Res 1995;60:495-504.

32 Bales KR, Verina T, Dodel RC, et al. Lack of apolipoprotein E dramatically reduces amyloid B-peptide deposition. Nat Genet 1997;17:263-4.

33 Takacs L, Boross P, Tozser J, et al. Transforming growth factor-B induced protein, BIG-H3, is present in degraded form and altered localization in lattice corneal dystrophy type 1. Exp Eye Res 1998;66:739-45.

34 Kawasaki S, Nishida K, Quantock AJ, et al. Amyloid and Pro501Thr-mutated Big-h3 gene product co-localize in lattice corneal dystrophy type III-A. Am $\mathcal{f}$ Ophthalmol 1999;127:456-8.

35 Klintworth GK, Valnickova Z, Kielar RA, et al. Familial subepithelial corneal amyloidosis - a lactoferrin-related amyloidosis. Invest Ophthalmol Vis Sci 1997;38:2756-63.

36 Klintworth GK, Sommer JR, Obrian G et al. Familial subepithelial corneal amyloidosis (gelatinous drop-like dystrophy): exclusion of linkage to lactoferrin gene. Mol Vis 1998;4:31.

37 Kinoshita S, Yokoi N, Komuro A. Barrier function of ocular surface epithelium. In: Lass J, ed. Advances in corneal research. New York: Plenum Press, 1997:47-55.

38 Quantock AJ, Nishida K, Kinoshita S. Histopathology of recurrent gelatinous-drop-like corneal dystrophy. Cornea 1998;17:215-21. 